\title{
A Double-Blind, Placebo-Controlled Pilot Study to Evaluate the Effect of Calcium Fructoborate on Systemic Inflammation and Dyslipidemia Markers for Middle-Aged People with Primary Osteoarthritis
}

\author{
Romulus Scorei • Paul Mitrut • Iulian Petrisor • \\ Iulia Scorei
}

Received: 22 March 2011 / Accepted: 9 May 2011/

Published online: 24 May 2011

(C) The Author(s) 2011. This article is published with open access at Springerlink.com

\begin{abstract}
The objective of this pilot study was to determine whether 15 days of dietary supplementation with calcium fructoborate could acutely modulate inflammatory and lipid blood markers in individuals diagnosed with primary osteoarthritis. During 2 weeks, a placebocontrolled, randomized, double-blind study was conducted on 116 subjects that were initially recruited. Seventy-two subjects started the study, being divided into four groups, and only 60 completed the study as designed. The aim was to compare the effects of calcium fructoborate to placebo on subjects diagnosed with knee primary osteoarthritis. The obtained outcomes were inflammation biomarkers (C-reactive protein, fibrinogen, and erythrocyte sedimentation rate) and lipid markers (triglycerides, total cholesterol, LDL cholesterol, and HDL cholesterol). No serious adverse events were reported. The calcium fructoborate showed beneficial effect on the inflammatory markers for all groups subjected to the treatment when compared with the placebo group and slight changes in the lipid metabolism. This study suggests that short-term ( 2 weeks) calcium fructoborate supplementation in patients with osteoarthritis symptoms has a favorable prognosis on inflammation diseases.
\end{abstract}

Romulus Scorei, Paul Mitrut, Iulian Petrisor and Iulia Scorei contributed equally to this work.

Trial registration: ClinicalTrials.gov number: ISRCTN46679573.

R. Scorei $(\bowtie)$

Biochemistry Department, University of Craiova, 13 A.I. Cuza Street, 200585 Craiova, Dolj, Romania e-mail: romulus_ion@yahoo.com

P. Mitrut

Department of Internal Medicine, University of Medicine and Pharmacy of Craiova, Craiova, Dolj, Romania

e-mail: centrul_renasterea@rdscv.ro

I. Petrisor

Department of Physics, University of Craiova, 13 A.I. Cuza Street, 200585 Craiova, Dolj, Romania e-mail: ipetri2@yahoo.com

I. Scorei

Neuropsychiatry Hospitals, Craiova, Dolj, Romania

e-mail: idscorei@yahoo.com 
Keywords Osteoarthritis · Systemic inflammation · Dyslipidemia markers · Calcium fructoborate $\cdot$ Dietary supplementation $\cdot$ Double-blind, placebo-controlled pilot study

$\begin{array}{ll}\text { Abbreviations } & \\ \text { CF } & \text { Calcium fructoborate } \\ \text { OA } & \text { Osteoarthritis } \\ \text { CRP } & \text { C-reactive protein } \\ \text { FBR } & \text { Fibrinogen } \\ \text { CVD } & \text { Cardiovascular disease } \\ \text { ESR } & \text { Erythrocyte sedimentation rate } \\ \text { NSAIDs } & \text { Nonsteroidal anti-inflammatory drugs } \\ \text { NSS } & \text { Neuropathy symptoms score } \\ \text { HDL cholesterol } & \text { High-density lipid cholesterol } \\ \text { LDL cholesterol } & \text { Low-density lipid cholesterol } \\ \text { TC } & \text { Total cholesterol } \\ \text { NCEP } & \text { National Cholesterol Education Program } \\ \text { SD } & \text { Standard deviation } \\ \text { TNF- } \alpha & \text { Tumor necrosis factor- } \alpha \\ \text { LPS } & \text { Lipopolysaccharide } \\ \text { COX-2 } & \text { Cyclooxygenase-2 }\end{array}$

\section{Introduction}

Many epidemiological and controlled animal and human experiments have provided evidence for the use of boron as a safe and effective treatment for some forms of osteoarthritis (OA) [1]. By examining the relationship between boron administration and OA prevalence around the world, researchers have discovered that in the areas where boron intake is $1 \mathrm{mg}$ or less per day, the estimated incidence of arthritis is between $20 \%$ and $70 \%$. In contrast, in areas where boron intake is usually 3-10 mg per day, the arthritis percentage is lower, ranging from zero to only $10 \%$. This remarkable finding is a compelling evidence of the fact that abundant intake of dietary boron can confer strong protection against the development of OA $[2,3]$. An analytical study showed that the boron concentration is lower in femur heads, bones, and synovial fluid of OA patients as compared with patients without OA. Moreover, surgeons have observed that the bones of patients that had used boron supplementation were harder to cut than those of patients who had not used these supplements [4]. The most convincing evidence for boron usage in the case of OA patients comes from a double-blind placebo boron supplementation trial conducted in Australia [5, 6] reporting that boron supplementation may improve symptoms for people with $\mathrm{OA}$ and rheumatoid arthritis [6]. Experimental studies on arthritic rats have led to an emerging hypothesis suggesting that boron reduces the risk of inflammatory disease by downregulating enzymes of the inflammatory response and has a beneficial immunomodulatory effect in the arthritic rats [7-9].

Recent studies have focused on the association between primary OA and dyslipidemia $[10,11]$. Many researchers have observed that cardiovascular disease (CVD) and OA often coexist in patients; consequently, it has been hypothesized that vascular disease may play a pathogenic role in OA, acting in part via lipid metabolic pathways [12]. The definitions for dyslipidemia, as defined by the NCEP guidelines, include total cholesterol (TC), $\geq 200 \mathrm{mg} / \mathrm{dL}$; low-density lipoprotein (LDL) cholesterol, $\geq 130 \mathrm{mg} / \mathrm{dL}$; triglycerides, $\geq 150 \mathrm{mg} / \mathrm{dL}$; highdensity lipoprotein (HDL) cholesterol, $<40 \mathrm{mg} / \mathrm{dL}$; and TC/HDL ratio, $\geq 6.5$ [13]. Previous 
studies have demonstrated an association among OA evolution, dyslipidemia, and inflammation as measured by systemic marker levels [14-16]. C-reactive protein (CRP), one of the most useful markers of systemic inflammation, has recently been identified as a marker of OA with clinical significance. CRP levels are moderately high for patients with OA as compared with the normal controls $[16,17]$. Of great clinical significance are CRP levels, with reference values below $0.5 \mathrm{mg} / \mathrm{dL}$ in OA patients $[18,19]$. Increased levels have been associated with the disease evolution as well as with the clinical aggravation, as an unspecific response to inflammations and infections [20-22].

Calcium fructoborate $(\mathrm{CF})$ is used as a recent nonpharmaceutical therapy for osteoarthritis treatment $[23,24]$. CF is a complex of calcium, fructose, and boron and is naturally found in fresh and dried fruits, vegetables, herbs, and wine. This form of boron is not only safe but also bioavailable compared with other commercial forms of boron [23]. Its structural formula is $\mathrm{Ca}\left[\left(\mathrm{C}_{6} \mathrm{H}_{10} \mathrm{O}_{6}\right)_{2} \mathrm{~B}\right]_{2} \cdot 4 \mathrm{H}_{2} \mathrm{O}$, identical with the one of a natural product [24].

An open label pilot study, authored by N. Miljkovic and colleagues from the Orthopedic Clinic of the University from Novi Sad, Novi Sad, Yugoslavia, was conducted. The purpose of the study was to investigate the effects of CF on OA symptoms. The study included 20 patients with mild, medium, or severe forms of OA. Two criteria for assessment were used: the Western Ontario McMaster University Osteoarthritis Index and Newnham criteria. After the administration of CF, the results were quite impressive: the pain was strongly diminished, the joint rigidity disappeared, and mobility and flexibility were improved [23, 24].

Our previous investigations have been summarized in two reviews $[23,24]$ that have revealed an anti-inflammatory property of $\mathrm{CF}$ on cellular cultures. In addition, we hypothesized that $\mathrm{CF}$ might have dual roles as both an anti-inflammatory and anti-oxidant agent, with modifying effect on lipid metabolism [23, 24].

This study investigates whether CF can relieve OA symptoms in selected subjects. Scientists have hypothesized that CF may have a role in diminishing inflammation-related pain, joint stiffness and other discomforts associated with OA [25-27]. Because OA discomfort is often invariably related to joint inflammation, this study approaches the CF effect on inflammatory blood markers levels such as CRP, fibrinogen (FBR), and on erythrocyte sedimentation rate (ESR) and on lipid metabolism markers because it has been suggested that boron is involved in both mechanisms [23].

When analyzing inflammatory markers, the 2-week time interval for the CF dietary supplementation was long enough to confirm our previous results obtained in vitro. Because the general characteristic of the placebo effect has a slightly delayed onset and a relatively short duration (from 2 to 6 weeks as cited in the literature) [28], a time interval of 2 weeks was chosen for this trial to more accurately observe the short-term efficacy of CF. This pilot study is only a bridge for a future, more complex research study regarding the effects of CF on OA symptoms.

\section{Methods and Materials}

Study Design and Selection of Patients

The study was placebo controlled, randomized, double blind with four groups of subjects. Patient recruitment took place from March 10, 2009 to August 30, 2009 at the second Medical Clinic, Craiova Emergency Hospital, Romania, from the surrounding community. At the 
screening visit, after providing written informed consent, each participant underwent a screening interview. Based on the screening, subjects were declared eligible to proceed if all inclusion criteria were fulfilled and no exclusion criteria were met. This single-center trial was approved by the Institutional Ethics Committee of the University of Medicine and Pharmacy from Craiova, Romania, according to decision no. 364 from March 2008. The trial is also in agreement with the Helsinki Declaration from 1975, which was revised in 1983.

\section{Patients' Characteristics}

The number of total enrolled patients was 116 (see Fig. 1). Not all enrolled subjects were included in the intent-to-treat (ITT) population. This ITT population was defined as being all the subjects who received the product and who had some follow-up evaluation. Fortyfour people did not meet inclusion criteria or refused to participate were not taken into consideration for the ITT analysis. Thus, the total number of subjects that were included in the ITT analysis was 72. These 72 patients were divided into four groups (19 in group 1, 18 in group 2, 17 in group 3, and 18 in the placebo group), but 12 of them did not meet the entire protocol.

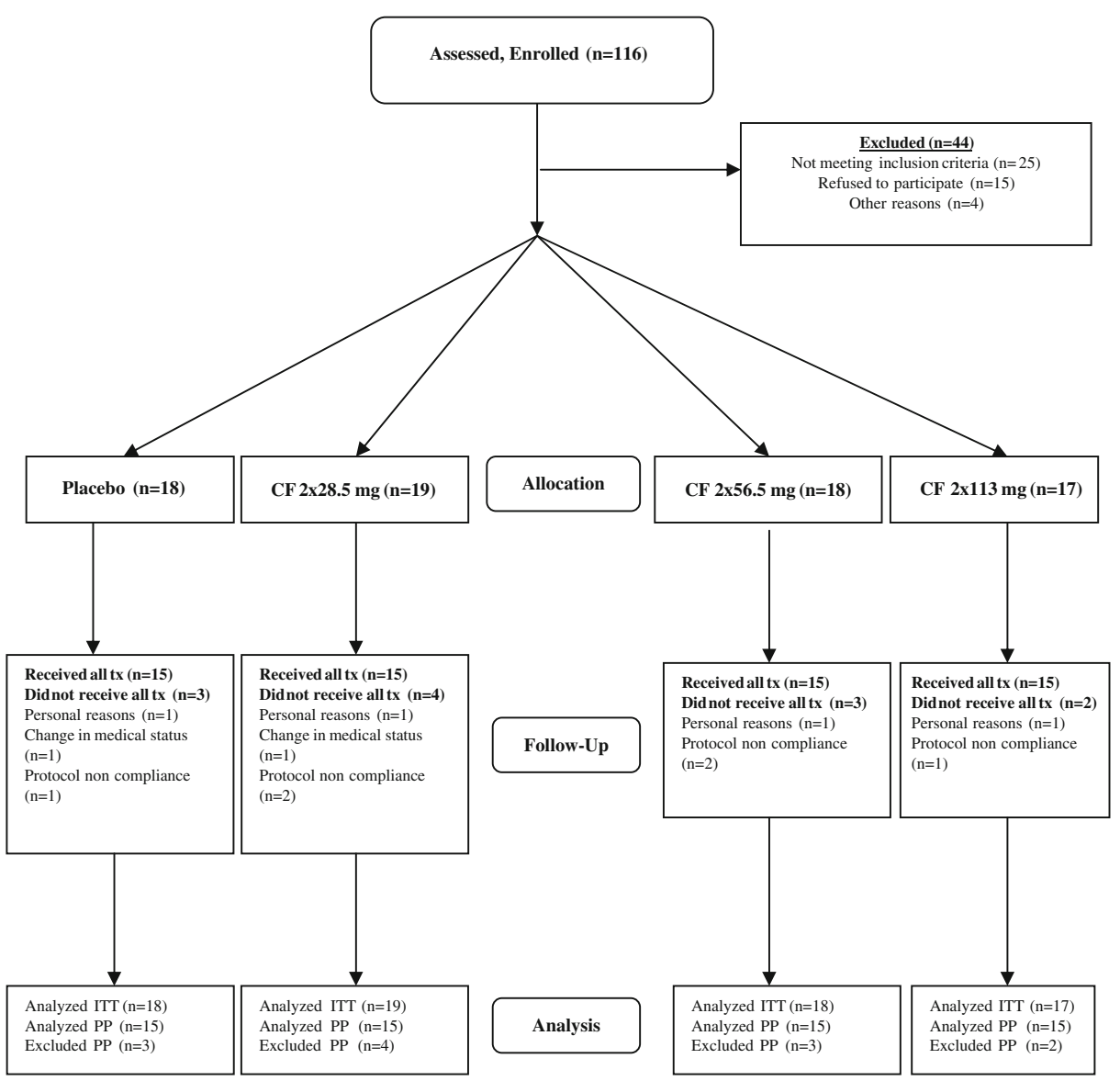

Fig. 1 Flow chart for patient recruitment 
From the total number of patients included in the study $(n=116)$, only 60 completed the 2-week treatment period. Age span was between 59 and 68 years, and the number of women was higher than the number of men (female, $43(71.66 \%)$ vs. male, $17(28.33 \%)$ ). There were 51 rural patients and nine urban patients. The boron dietary intake was calculated to be between 1.9 and $2.2 \mathrm{mg}$ boron per day, uniformly distributed between genders. The number of patients with dyslipidemia and the number of those with nonspecific inflammation was heterogeneous between groups (ranging from 66\% for group 2 to $93 \%$ for group 1 and $53 \%$ for group 2 to $93 \%$ for the placebo group, respectively). The baseline demographic characteristics of patients that successfully completed the study are given in Table 1 .

\section{Participants Inclusion Criteria}

Men and nonpregnant women, between 40 and 85 years old, with primary OA of at least one knee were included. Primary OA was defined by the deterioration and abrasion of the articular cartilage (joint space narrowing) or by the formation of a new bone (osteophytes) at the knee joint surface (medial tibiofemoral, lateral tibiofemoral, or patellofemoral). This fact was demonstrated upon radiological examination that was performed within the previous 3 months.

\section{Participants Exclusion Criteria}

Subjects with digestion problems, with fever and/or under treatment with antibiotics, with fructose intolerance and those taking any painkillers and/or vitamin B6 and aspirin were excluded from the study.

\section{Study Visits and Administration}

The study used a commercial dietary supplement FruiteX-B ${ }^{\circledR}$ trademark, registered by the FutureCeuticals Company from the USA. FruiteX-B ${ }^{\circledR}$ was scientifically proven as being identical to naturally occurring plant-based boron carbohydrate, CF [29].

Table 1 Baseline demographic characteristics of patients that successfully completed the study

\begin{tabular}{lllll}
\hline Characteristics & \multicolumn{2}{l}{ Patients groups } & & \\
\cline { 2 - 5 } & Placebo $^{\mathrm{a}}$ & Group 1 & Group 2 & Group 3 \\
\hline Number of patients per group & 15 & 15 & 15 & 15 \\
Gender (M/F) & $3: 12$ & $3: 12$ & $7: 8$ & $4: 11$ \\
Age (mean (SD), year) & $67.6(5.5)$ & $68.2(6.6)$ & $59.8(8.8)$ & $64.8(10)$ \\
Environment (rural/urban) & $15: 0$ & $15: 0$ & $9: 6$ & $12: 3$ \\
Daily boron dietary intake (mg/day) & $2.2(0.7)$ & $2.1(0.8)$ & $1.9(0.5)$ & $2.0(0.4)$ \\
Boron supplemented with CF (mg boron/day) & 0 & 1.5 & 3.0 & 6.0 \\
Patients with dyslipidemia ${ }^{\text {b }}$ (no. (\%)) & $11(73.3)$ & $14(93.3)$ & $10(66.6)$ & $12(80)$ \\
Patients with inflammations $^{\mathrm{c}}$ (no. (\%)) & $14(93.3)$ & $12(80)$ & $8(53.3)$ & $11(73.3)$ \\
\hline
\end{tabular}

\footnotetext{
${ }^{\text {a }}$ Placebo has $113 \mathrm{mg}$ of fructose

${ }^{\mathrm{b}}$ Patients with LDL at $>130$ and cholesterol of $>200$

${ }^{\mathrm{c}}$ Patients with CRP of $>0.5$
} 
The four subjects groups are described as follows:

- Group 1: $28.5 \mathrm{mg} \mathrm{CF}$ (1.5 mg boron/day) twice per day

- Group 2: $56.5 \mathrm{mg} \mathrm{CF}$ (3.0 mg boron/day) twice per day

- Group 3: $113 \mathrm{mg} \mathrm{CF} \mathrm{(6.0} \mathrm{mg} \mathrm{boron/day)} \mathrm{twice} \mathrm{per} \mathrm{day}$

- Placebo group: $120 \mathrm{mg}$ placebo twice per day. Placebo material was based only on fructose

The duration of the treatment was 2 weeks. Two capsules were administered per day and were taken orally with meals. The subjects' interviewers carried out a survey of dietary intake. They presented tableware and food models and investigated the meal intake on two different weekdays and one weekend day, relying on the recall method. Nutrient intake was calculated by the DietSYS+Plus usage (version 5.9) and dietary analysis program (Block Dietary Data Systems). The DietSYS+Plus database, a software that analyzes nutrients, was expanded for the present study to include dietary boron values in the Romanian consumed foods. After computing nutrients intake per subject, intake percentage was calculated in relation to the Dietary Reference Intakes for Romania [30, 31]. Subsequently, using the boron content database of the foods commonly consumed by the Romanian urban and rural people, boron intake was calculated. The computation was based on an analytical boron nutrient database that was created in Romania and previously developed for estimating boron intake (Scorei et al., unpublished results).

\section{Outcomes Measures (Biochemical Parameters)}

For biochemical analyses, venous blood samples were taken in the morning after fasting both at the beginning of the study and after 2 weeks of treatment. Commercially available collection tubes without anticoagulant were used to collect blood for the determination of biochemical parameters. Basic biochemical parameters, such as lipid profile (total, HDL, and LDL cholesterol) and inflammatory markers (CRP) were analyzed in serum using standard biochemical procedures. For the inflammatory markers ESR and FBR, anticoagulant was used. Enzymatic colorimetry methods using commercial kits (Boehringer Mannheim, Germany) and a Hitachi 911 automatic chemistry analyzer [32] measured cholesterol and triglyceride. Assays for CRP were performed using Tina-quant ${ }^{\circledR}$ immunoturbidimetric kit for CRP also available from Boehringer Mannheim Diagnostics, and the applications were developed for the BM/ Hitachi 911 [33]. The ESR was determined by the Westergren method using anticoagulant (ethylenediaminetetraacetate)-containing whole blood [34]. The ratio between blood and anticoagulant was 4:1. The reading is done on the integral blood at room temperature after at most $2 \mathrm{~h}$ after blood donation. FBR levels were determined in citrated plasma using a kinetic method, as described by Hemker et al. [35]. The blood donation was realized a jeun (on fasting-12 h of post) from venous blood in vacutainers. The serum was separated by centrifugation.

\section{Safety Assessment}

Three emergency telephone numbers were given to the subjects to maintain contact during the study in case they had any adverse events or other concerns related to the study. Each subject was interviewed during site visits to solicit information on possible adverse effects they might have encountered. Participants were instructed to inform the test supervisor if they chose to discontinue the study due to adverse effects. 
Statistical Analyses

The CF or placebo effect was evaluated with two-way randomized block analysis of variance. Microsoft Excel software was used for the statistical analysis. Statistical significance was defined at the level of $95 \%(p<0.05)$. Results are expressed as means \pm SD.

\section{Results}

\section{Inflammation Biomarkers}

For group 1 (see Table 2), there were significant decreases in ESR levels over the 2-week time interval as compared with the baseline $(-10.25 \%, p<0.05)$. At the same time, the placebo group's ESR level increased $(+36.36 \%, p<0.05)$.

For FBR level, we found a statistical significance but only for group 1 and the placebo group $(p<0.05)$. Group 1 showed a significant improvement in comparison to the baseline $(-13.73 \%)$, whereas the placebo group presented a small increase in the FBR level $(+4.1 \%)$.

CRP levels showed statistically significant improvements only for group 1 and the placebo group $(p<0.05)$. The most accurate results were obtained for group $1(-60.25 \%$ compared with the baseline). For the placebo group, the results were $+5.47 \%$ in comparison to the baseline.

The inflammatory markers were the most convincing evidence that the boron supplementation had an effect in the osteoarthritis subjects. These were convincing because, if all the boron-supplemented participants were lumped together, it appears that

Table 2 Efficiency-variable measurements of blood inflammatory markers for the intent-to-treat group after 2 weeks of supplementation with $\mathrm{CF}$

\begin{tabular}{|c|c|c|c|c|}
\hline \multirow[t]{2}{*}{ Variable (measurement) } & \multicolumn{4}{|c|}{ Patients groups } \\
\hline & Placebo & Group 1 & Group 2 & Group 3 \\
\hline $\operatorname{ESR}(p)^{\mathrm{a}}$ & 0.00058 & 0.02893 & 0.37639 & 0.07280 \\
\hline Baseline (mean (SD)) & $19.8(3.2)$ & $19.5(3.5)$ & $18.5(6.4)$ & $18.9(2.3)$ \\
\hline Final (mean (SD)) & $27(4.4)$ & $17.5(2.7)$ & $16.3(5.9)$ & $17.3(3.1)$ \\
\hline Change $(95 \% \mathrm{CI})$ & 7.2 & -2 & -2.2 & -1.6 \\
\hline$\%$ change from baseline & 36.36 & -10.25 & -11.9 & -8.5 \\
\hline $\operatorname{FBR}(p)^{\mathrm{a}}$ & 0.04553 & 0.00058 & 0.35822 & 0.36227 \\
\hline Baseline (mean (SD)) & $365(20)$ & $364(10)$ & $340(29)$ & $358(15)$ \\
\hline Final (mean (SD)) & $380(19)$ & 314 (14) & $333(16)$ & $343(15)$ \\
\hline Change $(95 \% \mathrm{CI})$ & 15 & -50 & -7 & -15 \\
\hline$\%$ change from baseline & 4.10 & -13.73 & -2.05 & -4.18 \\
\hline $\operatorname{CRP}(p)^{\mathrm{a}}$ & 0.00540 & 0.02453 & 0.06964 & 0.11227 \\
\hline Baseline (mean (SD)) & $0.73(0.12)$ & $0.78(0.2)$ & $0.75(0.2)$ & $0.57(0.19)$ \\
\hline Final (mean (SD)) & $0.77(0.07)$ & $0.31(0.02)$ & $0.55(0.24)$ & $0.47(0.17)$ \\
\hline Change $(95 \% \mathrm{CI})$ & 0.04 & -0.47 & -0.2 & -0.1 \\
\hline$\%$ change from baseline & 5.47 & -60.25 & -26.66 & -17.54 \\
\hline
\end{tabular}

${ }^{\text {a }}$ Statistical significance from baseline 
there would be no question that ESR, FBR, and CRP were reduced in these participants but not in the ones receiving the placebo.

\section{Dyslipidemia Markers}

During the short period of the study, both triglycerides and HDL cholesterol did not significantly change from baseline in all groups $(p>0.05)$. The lipid findings (see Table 3 ) were unconvincing that boron had any real physiological significant effect on "dyslipidemia." Even groups 3 and 4 are combined, boron would not have a significant effect on cholesterol or LDL cholesterol. Only in group 1, a significant reason was obtained and this was the fortunate small standard deviation in this group. Based on only two measurements (at the beginning and end), the variability shown groups 3 and 4 is a more expected finding.

\section{Discussion}

The current study is the first trial clinical study to evaluate the efficacy of CF in OA. This study also provides important information regarding the possible molecular mechanisms of an antiinflammatory compound with an identical natural origin in the treatment of OA. We have

Table 3 Efficiency-variable measurements of blood dyslipidemia markers for the intent-to-treat group after 2 weeks of supplementation with CF

\begin{tabular}{|c|c|c|c|c|}
\hline \multirow[t]{2}{*}{ Variable (measurement) } & \multicolumn{4}{|c|}{ Patients groups } \\
\hline & Placebo & Group 1 & Group 2 & Group 3 \\
\hline Triglycerides $(p)^{\mathrm{a}}$ & 0.36767 & 0.42201 & 0.09214 & 0.30010 \\
\hline Baseline (mean (SD)) & $121(11)$ & $137(15)$ & $188(15)$ & $141(13)$ \\
\hline Final (mean (SD)) & $130(15)$ & $128(16)$ & $145(22)$ & $138(12)$ \\
\hline Change $(95 \% \mathrm{CI})$ & 9 & -9 & -43 & -3 \\
\hline$\%$ change from baseline & 7.5 & -6.5 & -22.87 & -2.1 \\
\hline Cholesterol $(p)^{\mathrm{a}}$ & 0.16336 & 0.01378 & 0.14875 & 0.27139 \\
\hline Baseline (mean (SD)) & $222(13)$ & $244(10)$ & $230(69)$ & $260(78)$ \\
\hline Final (mean (SD)) & $234(10)$ & $222(9)$ & $224(45)$ & $255(70)$ \\
\hline Change $(95 \% \mathrm{CI})$ & 12 & -22 & -6 & -5 \\
\hline$\%$ change from baseline & 5.4 & -9.01 & -2.6 & -1.92 \\
\hline HDL cholesterol $(p)^{\mathrm{a}}$ & 0.19320 & 0.15895 & 0.38799 & 0.11081 \\
\hline Baseline (mean (SD)) & $47(8)$ & $53(3)$ & $49(7)$ & $55(11)$ \\
\hline Final (mean (SD)) & $51(4)$ & $54(4)$ & $50(6)$ & $58(13)$ \\
\hline Change $(95 \% \mathrm{CI})$ & 4 & 1 & 1 & 3 \\
\hline$\%$ change from baseline & 8.51 & -3.77 & 2.04 & 5.45 \\
\hline LDL cholesterol $(p)^{\mathrm{a}}$ & 0.10529 & 0.00555 & 0.42315 & 0.15522 \\
\hline Baseline (mean (SD)) & $150(9)$ & $164(6)$ & $143(7)$ & $175(20)$ \\
\hline Final (mean (SD)) & $160(8)$ & $144(6)$ & $144(10)$ & $170(16)$ \\
\hline Change $(95 \% \mathrm{CI})$ & 10 & -20 & 1 & -5 \\
\hline$\%$ change from baseline & 6.66 & -12.19 & 0.69 & -2.85 \\
\hline
\end{tabular}

${ }^{a}$ Statistical significance from baseline 
demonstrated that $\mathrm{CF}$ has potential efficacy in terms of reducing pain and improving the physical ability of OA patients [24]. CRP, FBR, and ESR levels were used to monitor disease activity and to observe the subjects' responses to treatment. Increased CRP levels have suggested that it might be associated with the disease evolution in patients with OA [36]. Besides that, ESR is not associated with clinical severity in patients with knee or hip OA [16]. In addition, CRP levels could be predictive for OA disease progression [21]. CRP levels have a stronger association with osteophyte production than with joint narrowing [37]. Prior findings have shown that CVD and OA often coexist in patients and CVD could play a pathogenic role in OA $[21,22]$. In this study, the obtained results demonstrate that in the case of OA associated with dyslipidemia, CF might provide a favorable prognostic for cardiovascular diseases, but the data are not sufficiently conclusive. Consequently, dietary supplementation with CF shows a slightly life-quality improvement for individuals suffering of OA associated with dyslipidemia.

Previous studies have showed that the optimum boron dietary intake is about $3 \mathrm{mg}$ boron per day and that it may provide protection against some types of cancers (prostate, breast, cervical and lung) [38, 39]. Osteoporosis and OA patients need around $3 \mathrm{mg}$ of boron per day [23] and we tried to assure this boron intake for the subjects of the study. The mechanisms by which CF exerts beneficial effects on systemic inflammatory and dyslipidemia markers are still unclear but some of its molecular biological in vitro activities are known. CF inhibits superoxide within cells $[25,26]$. CF stimulates osteoblast differentiation from bone narrowing. In addition, it acts synergistically with dexamethasone to increase bone mineralization [40]. $\mathrm{CF}$ induces an inhibition of IL-1 $\beta$, IL- 6 , and NO released in the culture media and increases TNF- $\alpha$ production. It has no effect on LPS-induced COX-2 protein expression [27].

Summing up, the presented data have important implications for new strategy development for preventing OA and dyslipidemia associated with boron supplementation. The final target is cardiovascular disease prevention. In a recent clinical trial [41], we have demonstrated the favorable effects of resveratrol combined with CF on the clinical and inflammatory status of patients with stable angina pectoris (Militaru et al., unpublished results).

The next objective of our research team is to broaden the investigation because the presented observations belong to just a pilot study with a short time duration.

In conclusion, with this experimental design, the presented study suggests that short-term $\mathrm{CF}$ supplementation (only 15 days) can increase the quality of life for OA patients, with a favorable prognosis for inflammatory states. The importance of this study is related to the beneficial actions of CF on systemic inflammation and perturbation of lipid metabolism for elderly individuals who otherwise might have an unfavorable prognosis in cardiovascular diseases. This study presents preliminary results that require further experimentation. A longer supplementation period is needed to ascertain whether $\mathrm{CF}$ is an effective anti-inflammatory agent.

Acknowledgment This study was supported by the Natural Research, Ltd. (Romania), project no.12/2008.

Open Access This article is distributed under the terms of the Creative Commons Attribution Noncommercial License which permits any noncommercial use, distribution, and reproduction in any medium, provided the original author(s) and source are credited.

\section{References}

1. Newnham RE (1991) Arthritis or skeletal fluorosis and boron. Int Clin Nutr Rev 11:68-70

2. Newnham RE (1994) Essentiality of boron for healthy bones and joints. Environ Health Prospect 102 (7):83-85 
3. Korkmaz M, Sayl U, Sayl BS, Bakirdere S, Titretir S, Yavuz Ataman O, Keskin S (2007) Estimation of human daily boron exposure in a boron-rich area. Brit J Nutr 98:571-575

4. Helliwell TR, Kelly SA, Walsh HP, Klenerman L, Haines J, Clark R, Roberts NB (1996) Elemental analysis of femoral bone from patients with fractured neck of femur or osteoarthritis. Bone 18:151-157

5. Newnham RE (1989) Boron problems and its essential nature. In: Chazot G, Abdulla M, Arnaud P (eds) Current trends in trace elements research. Smith-Gordon, Nishimura, pp 89-91

6. Travers RL, Rennie GC, Newnham RE (1990) Boron and arthritis: the results of a double-blind pilot study. J Nutr Med 1:127-132

7. Hunt CD, Idso JP (1999) Dietary boron as a physiological regulator of the normal inflammatory response: a review and current research progress. J Trace Elem Exp Med 12:221-233

8. Hunt CD (2002) Dietary boron is a physiological regulator of the normal inflammatory response. In: Trace elements in man and animals, part 5. Springer, New York. pp 1071-1076, doi:10.1007/0-306-47466-2 327

9. Nielsen FH (1994) Biochemical and physiologic consequences of boron deprivation in humans. Environ Health Prospect 102:59-63

10. Singh G, Miller JD, Lee FH, Pettitt D, Russell MW (2002) Prevalence of cardiovascular disease risk factors among US adults with self-reported osteoarthritis: data from the Third National Health and Nutrition Examination Survey. Am J Manag Care 8(suppl):S428-S430

11. Davies-Tuck M, Hanna F, Davis SR, Bell JR, Davison SL, Wluka AE, Adams J, Cicuttini FM (2009) Total cholesterol and triglycerides are associated with the development of new bone marrow lesions in asymptomatic middle-aged women - a prospective cohort study. Arthritis Res Ther 11:R181

12. Kadam UT, Jordan K, Croft PR (2004) Clinical comorbidity in patients with osteoarthritis: a case-control study of general practice consulters in England and Wales. Ann Rheu Dis 63:408-414

13. Persell SD, Lloyd-Jones DM, Baker DW (2006) National Cholesterol Education Program risk assessment and potential for risk misclassification. Prev Med 43:368-371

14. Van Leeuwen MA (1994) Acute phase proteins in the monitoring of inflammatory disorders. Baillières Clin Rheumatol 8(3):531-552

15. Sipe JD (1995) Acute-phase proteins in osteoarthritis. Semin Arthritis Rheum 25(2):75-86

16. Wolfe F, Goldberg R (1997) The C-reactive protein but not erythrocyte sedimentation rate is associated with clinical severity in patients with osteoarthritis of the knee or hip. J Rheumatol 24:1486

17. Conrozier T, Chappuis-Cellier C, Richard M, Mathieu P, Richard S, Vignon E (1998) Increased serum Creactive protein levels by immunonephelometry in patients with rapidly destructive hip osteoarthritis. Rev Rhum Engl Ed 65(12):759-765

18. Dati F, Metzmann E (2005) Acute phase proteins. In: Proteins laboratory testing and clinical use. Media Print Taunusdruck GmbH, Frankfurt am Main. pp 52-53

19. Fischbach F (2004) Immunodiagnostics studies. In: A manual of laboratory and diagnostics tests, 7th edn. Williams \& Wilkins, Baltimore. pp 604-605

20. Tarik M, Husain MD, Kim DH (2002) C-reactive protein and erythrocyte sedimentation rate orthopedics. U P O J 15:13-16

21. Dessein PH, Stanwix AE (2001) Inflammatory arthritis and cardiovascular disease may share a common predisposition. Rheumatology 40:703-704

22. Dessein PH, Stanwix AE, Joffe BJ (2002) Cardiovascular risk in rheumatoid arthritis versus osteoarthritis: acute phase response related decreased insulin sensitivity and high-density lipoprotein cholesterol as well as clustering of metabolic syndrome features in rheumatoid arthritis. Arthritis Res 4: R5

23. Miljkovic D, Scorei IR, Cimpoiasu VM, Scorei ID (2009) Calcium fructoborate: plant-based dietary boron for human nutrition. J Diet Suppl 6:211-226

24. Scorei RI, Rotaru P (2011) Calcium fructoborate-potential anti-inflammatory agent. Biol Trace Elem Res. doi:10.1007/s12011-011-8972-6

25. Scorei R, Cimpoiasu VM, Iordachescu D (2005) In vitro evaluation of the antioxidant activity of calcium fructoborate. Biol Trace Elem Res 107:127-134

26. Scorei R, Ciubar R, Iancu C, Mitran V, Cimpean A, Iordachescu D (2007) In vitro effects of calcium fructoborate on fMLP stimulated human neutrophil granulocytes. Biol Trace Elem Res 118:27-37

27. Scorei RI, Ciofrangeanu C, Ion R et al (2010) In vitro effects of calcium fructoborate upon production of inflammatory mediators by LPS-stimulated RAW 264.7 macrophages. Biol Trace Elem Res 135:334344

28. Kayne SB (ed) (2009) Complementary and alternative medicine, 2nd edn. Pharmaceutical Press, London

29. Rotaru P, Scorei R, Harabor A, Dumitru MD (2010) Thermal analysis of a calcium fructoborate sample. Thermochim Acta 506:8-13

30. Vlad M, Zapirtan H, Creteanu E (2003) Nutritional status in adult population in relation to the food intake. Annual Report of IPH Cluj-Napoca, Romania 
31. Vlad M, Zapirtan H, Creteanu E (2008) Food Intake and nutritional status of the population. annual national syntheses. Institute of Public Health Cluj-Napoca, Romania

32. Lee DH, Hong SH, Song J, Min W-K, Kim JQ (1999) Fibrinogen gene polymorphism in a non-caucasian population. Clin Biochem 32:113-117

33. Flood J, Liedtke R, Mattenheimer H, Rothouse L, Trundle D, Vroon D, Whisler K, Collinsworth W (1990) A multicenter evaluation of the Boehringer Mannheim Hitachi 717 system. Clin Biochem 23:477-488

34. Sarban S, Kocyigit A, Yazar M, Isikan UE (2005) Plasma total antioxidant capacity, lipid peroxidation, and erythrocyte antioxidant enzyme activities in patients with rheumatoid arthritis and osteoarthritis. Clin Biochem 38:981-986

35. Hemker HC, Kop J, Willems GM (1979) Kinetic aspects of the interaction of blood clotting enzymes, VII: the relation between clotting time and clotting velocity. Thromb Haemost 41:309-313

36. Sharif M, Shepstone L, Elson CJ, Dieppe PA, Kirwan JR (2000) Increased serum C reactive protein may reflect events that precede radiographic progression in osteoarthritis of the knee. Ann Rheum Dis 59:7174

37. Spector TD, Hart DJ, Nandra D, Doyle et al (2005) Low-level increases in serum C-reactive protein are present in early osteoarthritis of the knee and predict progressive disease. Arthritis Rheum 40(4):723727

38. Scorei RI, Popa R (2010) Boron-containing compounds as preventive and chemotherapeutic agents for cancer. Anticancer Agents Med Chem 10(4):346-351

39. Scorei RI (2011) Calcium fructoborate: plant-based dietary boron as potential medicine for cancer therapy. Front Biosci S3(1):205-215

40. Manda D, Popa O, Vladoiu S, Dumitrache C (2009) Calcium fructoborate effect on osteoblast mineralization in vitro. Bone 44(2):S298-S299

41. World Health Organization (2010) International clinical trials registry platform search portal. Identifier ISRCTN02337806. Effects of resveratrol combined with calcium fructoborate (Fruitex B) in patients with stable angina pectoris. A 60 days double-blind-controlled pilot study. World Health Organization, Geneva. Available at: http://apps.who.int/trialsearch/trial.aspx?trialid=ISRCTN02337806 